\title{
Correction to: Domain agnostic online semantic segmentation for multi-dimensional time series
}

\author{
Shaghayegh Gharghabi ${ }^{1}$ (D) Chin-Chia Michael Yeh ${ }^{1} \cdot$ Yifei Ding $^{1} \cdot$ Wei Ding $^{2}$. \\ Paul Hibbing ${ }^{3}$. Samuel LaMunion ${ }^{3}$ - Andrew Kaplan ${ }^{3}$. Scott E. Crouter ${ }^{3}$. \\ Eamonn Keogh ${ }^{1}$
}

Published online: 14 February 2019

(c) The Author(s) 2019

\section{Correction to: Data Mining and Knowledge Discovery (2019) 33:96-130 https://doi.org/10.1007/s10618-018-0589-3}

The article Domain agnostic online semantic segmentation for multi-dimensional time series, written by Shaghayegh Gharghabi, Chin-Chia Michael Yeh, Yifei Ding,

The original article can be found online at https://doi.org/10.1007/s10618-018-0589-3.

Shaghayegh Gharghabi sghar003@ucr.edu

Chin-Chia Michael Yeh myeh003@ucr.edu

Yifei Ding

yding007@ucr.edu

Wei Ding

wei.ding@umb.edu

Paul Hibbing

phibbing@vols.utk.edu

Samuel LaMunion

slamunio@vols.utk.edu

Andrew Kaplan

akaplan7@vols.utk.edu

Scott E. Crouter

scrouter@utk.edu

Eamonn Keogh

eamonn@cs.ucr.edu

1 Department of Computer Science and Engineering, University of California, Riverside, USA

2 Department of Computer Science, University of Massachusetts Boston, Boston, USA

3 Department of Kinesiology, Recreation, and Sport Studies, The University of Tennessee Knoxville, Knoxville, USA 
Wei Ding, Paul Hibbing, Samuel LaMunion, Andrew Kaplan, Scott E. Crouter, Eamonn Keogh, was originally published electronically on the publisher's internet portal (currently SpringerLink) on 25 September 2018 without open access. With the author(s)' decision to opt for Open Choice, the copyright of the article changed on 21 January 2019 to (C) The Author(s) 2019 and the article is forthwith distributed under the terms of the Creative Commons Attribution 4.0 International License (http://creativecommons.org/licenses/by/4.0/), which permits use, duplication, adaptation, distribution and reproduction in any medium or format, as long as you give appropriate credit to the original author(s) and the source, provide a link to the Creative Commons license and indicate if changes were made.

Open Access This article is distributed under the terms of the Creative Commons Attribution 4.0 International License (http://creativecommons.org/licenses/by/4.0/), which permits unrestricted use, distribution, and reproduction in any medium, provided you give appropriate credit to the original author(s) and the source, provide a link to the Creative Commons license, and indicate if changes were made.

Publisher's Note Springer Nature remains neutral with regard to jurisdictional claims in published maps and institutional affiliations. 